\title{
Knowledge and practices regarding malaria and the National Treatment Guidelines among public health workers in Equatorial Guinea
}

\author{
Marta Blanco 1,2, Pablo Suárez-Sanchez 1,3, Belén García1,4, Jesús Nzang 1,4 , Policarpo Ncogo 1,4, Matilde Riloha ${ }^{5}$, \\ Pedro Berzosa ${ }^{1,6}$, Agustín Benito ${ }^{1,6}$ and María Romay-Barja ${ }^{1,6^{*}}$ (D)
}

\begin{abstract}
Background: In 2018, an estimated 228 million cases of malaria occurred worldwide. Countries are far from having achieved reasonable levels of national protocol compliance among health workers. Lack of awareness of treatment protocols and treatment resistance by prescribers threatens to undermine progress when it comes to reducing the prevalence of this disease. This study sought to evaluate the degree of knowledge and practices regarding malaria diagnosis and treatment amongst prescribers working at the public health facilities of Bata, Equatorial Guinea.

Methods: A cross-sectional survey was conducted in October-December 2017 amongst all public health professionals who attended patients under the age of 15 years, with suspected malaria in the Bata District of Equatorial Guinea. Practitioners were asked about their practices and knowledge of malaria and the National Malaria Treatment Guidelines. A bivariate analysis and a logistic regression model were used to determine factors associated with their knowledge.
\end{abstract}

Results: Among the 44 practitioners interviewed, 59.1\% worked at a Health Centre and $40.9 \%$ at the District Hospital of Bata. Important differences in knowledge and practices between hospital and health centre workers were found. Clinical diagnosis was more frequently by practitioners at the health centres $(p=0.059)$, while microscopy confirmation was more frequent at regional hospital (100\%). Intramuscular artemether was the anti-malarial most administrated at the health centres (50.0\%), while artemether-lumefantrine was the treatment most used at the regional hospital (66.7\%). Most practitioners working at public health facilities (63.6\%) have a low level of knowledge regarding the National Malaria Treatment Guidelines. While knowledge regarding malaria, the National Malaria Treatment Guidelines and treatment resistances is low, it was higher amongst hospital workers than amongst practitioners at health centres.

Conclusions: It is essential to reinforce practitioners' knowledge, treatment and diagnosis practices and use of the National Malaria Treatment Guidelines in order to improve malaria case management and disease control in the region. A specific malaria training programme ensuring ongoing updates training is necessary in order to ensure that greater experience does not entail obsolete knowledge and, consequently, inadequate diagnosis and treatment practices.

\footnotetext{
*Correspondence: mromay@isciii.es

${ }^{1}$ Centro Nacional de Medicina Tropical, Instituto de Salud Carlos III, Madrid, Spain

Full list of author information is available at the end of the article
}

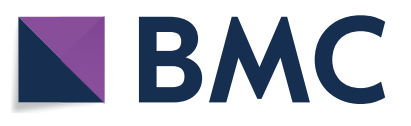

(c) The Author(s) 2021. This article is licensed under a Creative Commons Attribution 4.0 International License, which permits use, sharing, adaptation, distribution and reproduction in any medium or format, as long as you give appropriate credit to the original author(s) and the source, provide a link to the Creative Commons licence, and indicate if changes were made. The images or other third party material in this article are included in the article's Creative Commons licence, unless indicated otherwise in a credit line to the material. If material is not included in the article's Creative Commons licence and your intended use is not permitted by statutory regulation or exceeds the permitted use, you will need to obtain permission directly from the copyright holder. To view a copy of this licence, visit http://creativeco mmons.org/licenses/by/4.0/. The Creative Commons Public Domain Dedication waiver (http://creativecommons.org/publicdomain/ zero/1.0/) applies to the data made available in this article, unless otherwise stated in a credit line to the data. 


\section{Background}

In 2018, an estimated 228 million cases of malaria occurred worldwide. Fifteen countries in sub-Saharan Africa carry almost $80 \%$ of the global malaria mortality [1]. Children under five are the most vulnerable group affected by malaria [2]. In 2018, they accounted for $67 \%$ of all malaria deaths worldwide [1]. Malaria also has an important impact on health expenditure, days of work lost and school absenteeism [3].

Disease diagnosis and early treatment are of prime importance in order to reduce the rates of morbidity and mortality. Treating malaria-infected patients within $24-48 \mathrm{~h}$ after fever onset is likely to prevent further transmission of the parasite [4]. It is critical that populations living in malaria-endemic areas should have access to reliable diagnostics and effective treatment to control de disease.

Malaria is endemic in Equatorial Guinea with stable transmission, and it continues to be a major cause of morbidity and mortality among children under 5 years of age. The prevalence of malaria in 2011 in children under five was 13\% in the Insular Region and 59\% in the Continental Region [5].

National programmes for malaria control must adapt the World Health Organization (WHO) recommendations to the local context regarding the use of rapid diagnostic tests (RDT) or microscopy to confirm suspected malaria cases and the prescription of the most appropriate artemisinin-based combination therapy (ACT). ACT is considered a highly effective and well tolerated treatment, one that has contributed substantially to reducing global morbidity and mortality in the case of malaria [6]. However, the continued use of oral artemisinin-based monotherapy is considered to be one of the main reasons for the development and spread of resistance to artemisinin and its derivatives [7]. Unfortunately, countries are far from having achieved reasonable levels of national protocol compliance among health workers [8]. Lack of awareness of treatment protocols and treatment resistances by prescribers threatens to undermine progress when it comes to reducing the prevalence of this disease [9].

Health workers' knowledge and practices regarding malaria diagnosis and national treatment guidelines is crucial [10] and closely related to many socio-economic factors $[11,12]$, including the background of participants, their level of education, the type of health organization and years of experience [13].
In Equatorial Guinea, the National Programme for Malaria Control (NPMC) of the Ministry of Health and Social Welfare (MINSABS) updated its National Malaria Treatment Guidelines (NMTG) in 2008, establishing artesunate-amodiaquine (ASAQ) as first-line treatment for uncomplicated malaria. The use of oral artemisinin monotherapy was forbidden in Equatorial Guinea in 2014 [14]. Unfortunately, 9 years after the introduction of ASAQ therapy in Equatorial Guinea, compliance with the first-line treatment seems to be very poor in the Bata District [15].

Understanding local health workers' treatment and diagnostic practices and knowledge is important in terms of improving malaria case management and disease control. This study sought to evaluate, for the first time, the practices and degree of knowledge regarding malaria and the National Malaria Treatment Guidelines amongst prescribers working at the public health facilities of Bata, located in the Continental Region of Equatorial Guinea.

\section{Methods \\ Study design and setting}

Equatorial Guinea (EG) is a sub-Saharan country located in the Gulf of Guinea. The Bata District, located on the coast of the Continental Region of Equatorial Guinea, is the largest district in the country, with a population of 309,345 inhabitants. Its capital is the city of Bata, one of the two main cities of EG, alongside Malabo, the country's capital. The prevalence of malaria in children under 15 years of age is $41.2 \%$ [16].

The public health system structure of Bata District consists of 10 health centres, consisting of nine primary health care centres and one regional hospital, located in the city. Despite the state of public health institutions in the Bata District, patients have to pay for consultation, complementary tests and treatments. The management of these centres is heterogeneous and the prices, as well as the flow of patients and the availability of drugs, is different at each health facility. When data were collected for this study, only eight primary health care centres were operational (two rural centres and the rest urban).

The Equatorial Guinea NMTG recommends ASAQ as the first-line treatment for children $>2$ months of age with malaria, whilst quinine $(\mathrm{QN})$ is recommended for younger patients. Artemether-lumefantrine (AL) and QN remain second-line treatments if ASAQ is not effective. Intravenous artesunate is recommended for the management of severe malaria until the patient regains consciousness, then full ASAQ therapy should 
be administered. If artesunate is not available, quinine or artemether should be administered [17].

\section{Study population and data gathering}

This cross-sectional survey was conducted in OctoberDecember 2017 amongst all public health professionals who attended patients under 15 years old with suspected malaria in the Bata District of Equatorial Guinea. Practitioners were asked about their practices and knowledge of malaria and the National Malaria Treatment Guidelines (NMTG). Questions about their sociodemographic characteristics, the biological cycle of malaria parasites, malaria treatment practices, the recommendations given by the NMTG and resistance to anti-malarial drugs were included in the questionnaire. Details of the survey have been described previously [15].

\section{Data analysis}

A descriptive analysis of practitioners' characteristics was carried out using frequency tables for categorical variables and mean and standard deviation or median and interquartile range for normally and not-normally distributed continuous variables, respectively. A bivariate analysis was carried out, with the dependent variable being the practitioner's work centre: Health Centre or Regional Hospital. Differences in knowledge were assessed using the $\chi^{2}$ test. $P$ values below 0.05 were considered significant.

In order to assess the effect of socio-demographic variables on practitioners' knowledge of malaria and the NMTG, a knowledge index was calculated, taking into account the answers they gave to some of the survey questions [18]. To achieve a maximum score of 13 , the respondents had to know some general facts about malaria: that malaria is transmitted by a mosquito ( 1 point); symptoms of uncomplicated malaria such as fever, headache or weakness (1 point each); symptoms of severe malaria such as low level of consciousness, convulsions or respiratory depression (1 point each). Respondents also needed to know that diagnosis must be carried out using a microscope or a Rapid Diagnosis Test (1 point each). The survey also gauged whether they knew about different aspects of the NMTG, including: whether they were aware of the NMTG (1 point); the first line of treatment according to the NMTG in uncomplicated cases: ASAQ or Quinine (1 point); first-line treatment in complicated cases, such as intravenous (IV) AS, intravenous (IV) quinine or intramuscular (IM) artemether and oral treatment with ASAQ when possible (1 point). Practitioners also obtained 1 point if they knew about the existence of resistance to anti-malarial drugs. High and Low Knowledge of Malaria were defined as scores either above or within and below the overall median, respectively.
A logistic regression model was used to determine factors associated with a high knowledge of malaria score. The odds ratio (OR) and 95\% confidence interval (95\% $\mathrm{CI})$ were computed; p-values less than or equal to 0.05 were considered statistically significant. Data analysis was performed using IBM SPSS statistics 23.

\section{Results}

Out of a total of 44 practitioners who were interviewed, $59.1 \%$ worked at a Health Centre and $40.9 \%$ at the District Hospital of Bata (Table 1). Most of the practitioners at the hospital were women (83.3\%), compared to $53.8 \%$ at the health centres. The median age of practitioners was 36 years (IQR: $31-44)$ and they had a median experience of 3 years (IQR: 2-7); the practitioners at the health centres were older and had more years of experience. All

\begin{tabular}{|c|c|c|c|c|c|}
\hline & \multicolumn{2}{|c|}{ Health centre } & \multicolumn{3}{|c|}{ Hospital } \\
\hline & $\mathrm{n}$ & $\%$ & $\mathrm{n}$ & $\%$ & $P$ value \\
\hline \multicolumn{6}{|l|}{ Sex } \\
\hline Male & 12 & 46.15 & 3 & 16.67 & \\
\hline Female & 14 & 53.85 & 15 & 83.33 & 0.042 \\
\hline \multicolumn{6}{|l|}{ Age } \\
\hline $20-29$ & 1 & 3.85 & 3 & 16.67 & \\
\hline 30-39 & 13 & 50.00 & 12 & 66.67 & \\
\hline $40-49$ & 5 & 19.23 & 1 & 5.56 & \\
\hline $50-59$ & 6 & 23.08 & 2 & 11.11 & \\
\hline$>60$ & 1 & 3.85 & 0 & 0.00 & 0.246 \\
\hline \multicolumn{6}{|l|}{ Academic level } \\
\hline Medical degree & 10 & 38.46 & 18 & 100.00 & \\
\hline Nursing degree & 5 & 19.23 & 0 & 0.00 & \\
\hline Nursing diploma & 8 & 30.77 & 0 & 0.00 & \\
\hline Medical assistant & 3 & 11.54 & 0 & 0.00 & 0.001 \\
\hline \multicolumn{6}{|l|}{ Years of experience } \\
\hline$<5$ & 17 & 65.38 & 15 & 83.33 & \\
\hline $6-10$ & 2 & 7.69 & 3 & 16.67 & \\
\hline $11-20$ & 3 & 11.54 & 0 & 0.00 & \\
\hline$>20$ & 4 & 15.38 & 0 & 0.00 & 0.108 \\
\hline \multicolumn{6}{|l|}{ Malaria cases/day } \\
\hline$<10$ & 22 & 84.62 & 4 & 22.22 & \\
\hline $11-20$ & 4 & 15.38 & 9 & 50.00 & \\
\hline $21-30$ & 0 & 0.00 & 2 & 11.11 & \\
\hline$>30$ & 0 & 0.00 & 3 & 16.67 & 0.000 \\
\hline \multicolumn{6}{|c|}{$<15$ years old malaria cases/day } \\
\hline$<10$ & 24 & 92.31 & 4 & 22.22 & \\
\hline $11-20$ & 2 & 7.69 & 9 & 50.00 & \\
\hline $21-30$ & 0 & 0.00 & 2 & 11.11 & \\
\hline$>30$ & 0 & 0.00 & 3 & 16.67 & 0.000 \\
\hline
\end{tabular}


practitioners at the regional hospital were physicians, while only $38.5 \%$ at the health centres had a medical degree. At the regional hospital practitioners said to visit a significantly higher number of patients with malaria per day than practitioners at the health centres.

\section{General knowledge regarding malaria}

Regarding malaria transmission, $100 \%$ of practitioners knew that malaria is transmitted by a mosquito bite and $81.8 \%$ answered that the Plasmodium is the microorganism responsible for the disease, with no differences according to centre. Fever was mentioned by all practitioners, followed by vomiting (63.6\%), headache (59.1\%) and diarrhoea (50.0\%). Anaemia and splenomegaly were mentioned by 13.6 and $11.4 \%$ of practitioners, respectively, when asked about uncomplicated malaria signs and symptoms. An additional table file shows this in more detail (Table 2).

Regarding the symptoms of severe malaria, convulsion was the symptom most mentioned (88.6\%), being mentioned significantly more by practitioners at the regional hospital ( $p 0.048)$, followed by anaemia ( $47.7 \%)$ and prostration (27.3\%), with no significant differences between practitioners at the health centres and the regional hospital.

\section{Knowledge and practices regarding diagnostic and treatment}

Most of the practitioners said that malaria is diagnosed through clinical symptomatology, significantly more frequent at the health centres (Table 3). Microscopy confirmation for diagnosis was mentioned more frequently by practitioners at the regional hospital. Half of the health centre practitioners $(50.0 \%)$ also stated that malaria could be diagnosed using Rapid Diagnostic Tests (RDTs), compared to only $16.67 \%$ of the hospital practitioners $(p=0.03)$. Practitioners were asked about which diagnostic method they preferred to use and microscopy, when available, was the most mentioned (59.1\%), particularly by practitioners at the regional hospital (77.78\%).

When talking about known treatments for uncomplicated malaria in children under 15 years old, $86.4 \%$ of the practitioners answered ASAQ, this being mentioned significantly more by practitioners at the regional hospital. Quinine was also mentioned by $86.4 \%$ of the respondents, but without any differences according to the place of work. The following treatments most mentioned were $\mathrm{AL}$ and intramuscular artemether (AM) $(81.8 \%)$ with no significant differences according to place of work.

Concerning the most prescribed treatment for uncomplicated malaria in children less than 15 years old, significant differences emerged between treatment practices at the health centres and the regional hospital.
Table 2 Knowledge about malaria, signs and symptoms

\begin{tabular}{|c|c|c|c|c|c|}
\hline & \multicolumn{2}{|c|}{ Health centre } & \multicolumn{3}{|c|}{ Hospital } \\
\hline & $\mathbf{n}$ & $\%$ & $\mathbf{n}$ & $\%$ & $P$ value \\
\hline \multicolumn{6}{|l|}{ Malaria transmission } \\
\hline Mosquito bite & 26 & 100.00 & 18 & 100.00 & - \\
\hline \multicolumn{6}{|c|}{ Microorganism is responsible for the disease } \\
\hline Plasmodium & 22 & 84.62 & 14 & 77.78 & \\
\hline Other & 4 & 15.38 & 4 & 22.22 & 0.563 \\
\hline \multicolumn{6}{|c|}{ Signs and symptoms of malaria } \\
\hline Fever & 26 & 100.00 & 18 & 100.00 & - \\
\hline Anaemia & 5 & 19.23 & 1 & 5.56 & 0.194 \\
\hline Splenomegaly & 4 & 15.38 & 1 & 5.56 & 0.312 \\
\hline Diarrhoea & 15 & 57.69 & 7 & 38.89 & 0.220 \\
\hline Vomiting & 15 & 57.69 & 13 & 72.22 & 0.325 \\
\hline Headache & 16 & 61.54 & 10 & 55.56 & 0.691 \\
\hline Aching body & 4 & 15.38 & 1 & 5.56 & 0.312 \\
\hline Chills & 5 & 19.23 & 7 & 38.89 & 0.150 \\
\hline Loss of appetite & 11 & 42.31 & 8 & 44.44 & 0.888 \\
\hline Vertigo & 5 & 19.23 & 2 & 11.11 & 0.469 \\
\hline Sickness & 2 & 7.69 & 0 & 0.00 & 0.228 \\
\hline Weakness & 10 & 38.46 & 10 & 55.56 & 0.263 \\
\hline Abdominal pain & 6 & 23.08 & 3 & 16.67 & 0.604 \\
\hline \multicolumn{6}{|c|}{ Signs and symptoms of severe malaria } \\
\hline Loss of consciousness & 4 & 15.38 & 0 & 0.00 & 0.081 \\
\hline Prostration & 7 & 26.92 & 5 & 27.78 & 0.950 \\
\hline Convulsions & 21 & 80.77 & 18 & 100.00 & 0.048 \\
\hline Acidotic breathing & 1 & 3.85 & 0 & 0.00 & 0.400 \\
\hline Acute lung oedema & 0 & 0.00 & 1 & 5.56 & 0.224 \\
\hline Circulatory collapse & 1 & 3.85 & 1 & 5.56 & 0.789 \\
\hline Anaemia & 14 & 53.84 & 7 & 38.88 & 0.329 \\
\hline
\end{tabular}

Intramuscular artemether (AM) was the anti-malarial most mentioned by the practitioners at the health centres (50.0\%), while the-artemether-lumefantrine $(\mathrm{AL})$ was the treatment most mentioned by the practitioners at the regional hospital (66.7\%). Furthermore, the practitioners who said to prescribe AM mentioned that they did so in association with sulfadoxine-pyrimethamine; this was mentioned significantly more frequently by those working at the health centres (53.8\%) compared to the hospital $(5.6 \%)(p=0.001)$.

Regarding why they did not prescribe the first-line malaria treatment ASAQ, almost $60 \%$ of the practitioners mentioned its side-effects, without any differences according to work centres.

Concerning their knowledge of resistance to antimalarial treatments in the Bata District, $72.3 \%$ of practitioners said to know about the existence of anti-malarial resistance. About $61.1 \%$ of the hospital practitioners mentioned AM, when asked about which drugs $P$. falciparum had developed a resistance to, compared to only 
Table 3 Knowledge and practices regarding malaria diagnosis and treatment

\begin{tabular}{|c|c|c|c|c|c|}
\hline & \multicolumn{2}{|c|}{$\begin{array}{l}\text { Health } \\
\text { centre }\end{array}$} & \multicolumn{3}{|c|}{ Hospital } \\
\hline & $\mathbf{n}$ & $\%$ & $\mathbf{n}$ & $\%$ & $P$ value \\
\hline \multicolumn{6}{|l|}{ Malaria diagnostic procedures } \\
\hline Microscopy & 25 & 96.15 & 18 & 100.00 & 0.400 \\
\hline Clinical symptomatology & 25 & 96.15 & 14 & 77.78 & 0.059 \\
\hline $\mathrm{RDT}$ & 13 & 50 & 3 & 16.67 & 0.024 \\
\hline \multicolumn{6}{|l|}{ Method you prefer to use } \\
\hline Microscopy & 12 & 46.15 & 14 & 77.78 & \\
\hline Clinical symptomatology & 10 & 38.46 & 4 & 22.22 & \\
\hline RDT & 4 & 15.38 & 0 & 0.00 & 0.066 \\
\hline \multicolumn{6}{|c|}{$\begin{array}{l}\text { Treatments you know for uncomplicated malaria in children under } \\
15 \text { years }\end{array}$} \\
\hline ASAQ & 20 & 76.92 & 18 & 100.00 & 0.028 \\
\hline $\mathrm{AL}$ & 19 & 73.08 & 17 & 94.44 & 0.071 \\
\hline QUININE & 22 & 84.62 & 16 & 88.89 & 0.685 \\
\hline $\mathrm{SP}$ & 14 & 53.85 & 9 & 50.00 & 0.802 \\
\hline AM im & 21 & 80.77 & 15 & 83.33 & 0.828 \\
\hline AS oral & 17 & 65.38 & 12 & 66.67 & 0.930 \\
\hline$A S+S P$ & 4 & 15.38 & 6 & 33.33 & 0.152 \\
\hline ASMF & 3 & 11.54 & 3 & 16.67 & 0.626 \\
\hline Chloroquine & 2 & 7.69 & 2 & 11.11 & 0.698 \\
\hline
\end{tabular}

Treatment you prescribe to children under 15 years in cases of uncomplicated malaria

$\begin{array}{lrrrrl}\text { ASAQ } & 5 & 19.23 & 5 & 27.78 & \\ \text { AL } & 5 & 19.23 & 12 & 66.67 & \\ \text { QUININE } & 1 & 3.85 & 0 & 0.00 & \\ \text { AS } & 2 & 7.69 & 1 & 5.56 & \\ \text { AM im } & 13 & 50 & 0 & 0.00 & 0.003\end{array}$

What makes you choose the treatment you mention?

$\begin{array}{lrrrrl}\text { It is the most effective } & 17 & 65.38 & 12 & 66.67 & 0.93 \\ \text { It is the cheapest } & 2 & 7.69 & 3 & 16.67 & 0.356 \\ \text { Its availability } & 7 & 26.92 & 3 & 16.67 & 0.425 \\ \text { It is the safest } & 7 & 26.92 & 7 & 38.89 & 0.402 \\ \text { It is preferred by patients } & 5 & 19.23 & 1 & 5.56 & 0.194 \\ \text { It is indicated in the National } & 3 & 11.54 & 1 & 5.56 & 0.497 \\ \quad \text { Malaria Treatment Guide- } & & & & & \\ \quad \text { lines } & & & & & \\ \text { Why not prescribe ASAQ? } & 5 & 19.23 & 2 & 11.11 & 0.469 \\ \text { It is not available } & 14 & 53.85 & 12 & 66.67 & 0.395 \\ \text { Side-effects } & 1 & 3.85 & 0 & 0.00 & - \\ \text { It is not adapted to children } & 1 & 3.85 & 0 & 0.00 & - \\ \text { Patients do not like it } & 4 & 15.38 & 2 & 11.11 & 0.439 \\ \text { Others } & 4 & & \end{array}$

Do you know if there are resistances to any anti-malarial drug in the Bata District?

$\begin{array}{lrrrrr}\text { No } & 9 & 34.62 & 3 & 16.67 & \\ \text { Yes } & 17 & 65.38 & 15 & 83.33 & 0.166\end{array}$

Could you list which anti-malarial drugs have known resistances?

\begin{tabular}{lrrrrr} 
Chloroquine & 9 & 34.62 & 4 & 22.22 & 0.294 \\
AS & 1 & 3.85 & 5 & 27.78 & 0.034 \\
\hline
\end{tabular}

Table 3 (continued)

\begin{tabular}{|c|c|c|c|c|c|}
\hline & \multicolumn{2}{|c|}{$\begin{array}{l}\text { Health } \\
\text { centre }\end{array}$} & \multicolumn{3}{|c|}{ Hospital } \\
\hline & $\mathrm{n}$ & $\%$ & $\mathrm{n}$ & $\%$ & $P$ value \\
\hline AM & 4 & 15.38 & 11 & 61.11 & 0.002 \\
\hline SP & 2 & 7.69 & 1 & 5.56 & 0.638 \\
\hline ASAQ & 3 & 11.54 & 1 & 5.56 & 0.455 \\
\hline Quinine & 3 & 11.54 & 3 & 16.67 & 0.476 \\
\hline
\end{tabular}

$15.38 \%$ of the health centre practitioners ( $p$ value 0.002 ). Chloroquine was the second anti-malarial most mentioned by practitioners (29.5\%), with no differences between work centres. Resistance to artemisinin was also mentioned significantly more by practitioners at the regional hospital (27.8\%) than at the health centres (3.8\%).

\section{The National Malaria Treatment Guidelines (NMTG)}

Most of the practitioners at the health centres (57.7\%) said not to know the National Malaria Treatment Guidelines (Table 4), while most practitioners working at the regional hospital said to know it (66.7\%). Most of the practitioners who were aware of the Guidelines stated that they had heard about it through a colleague (39.1\%), followed by specific MINSABS training (34.8\%). Concerning the first-line treatment recommended in the NMTG for uncomplicated malaria in children less than 15 years old was, a $69.6 \%$ of practitioners mentioned ASAQ. However, only two practitioners answered correctly about the treatment protocol set out in the NMTG to treat a patient with severe malaria before transferring to the hospital, one from the hospital and one from a health centre, Regarding the treatment included in the NMTG for children less than 15 years old with severe malaria, $75.0 \%$ of practitioners working at the regional hospital answered correctly, while most of the practitioners working at the health centres cited other incorrect treatments. Most of the practitioners who knew the NMTG (65.2\%) stated that they did not have any difficulty in applying the protocol (Table 4).

\section{Knowledge-related index and factors}

The majority of Bata District practitioners (63.6\%) had a low Malaria Knowledge Index, with none of the 44 practitioners interviewed achieving the maximum score of 13 points. The total median score was seven, with most practitioners from the health centres $(76.92 \%)$ scoring Low and most of the practitioners from the regional hospital $(61.11 \%)$ scoring above the median. Figure 1 shows this in more detail. 
Table 4 National Malaria Treatment Guidelines (NMTG) knowledge and practices

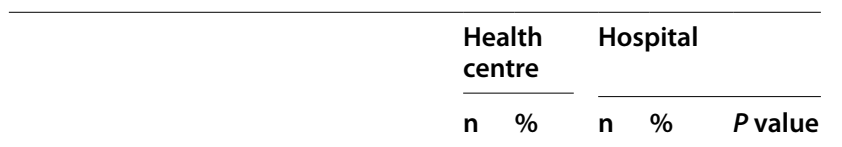

Do you know the NMTG of Equatorial Guinea?

\begin{tabular}{|c|c|c|c|c|c|}
\hline No & 15 & 57.69 & 6 & 33.33 & \\
\hline Yes & 11 & 42.31 & 12 & 66.67 & 0.099 \\
\hline \multicolumn{6}{|l|}{ How did you hear about the NMTG? } \\
\hline Specific MINSABS training & 4 & 36.36 & 4 & 33.33 & \\
\hline $\begin{array}{l}\text { Specific training of Centre's Manage- } \\
\text { ment }\end{array}$ & 0 & 0.00 & 1 & 8.33 & \\
\hline Work colleagues & 5 & 45.45 & 4 & 33.33 & \\
\hline Other training & 2 & 18.18 & 3 & 25.00 & 0.736 \\
\hline \multicolumn{6}{|c|}{$\begin{array}{l}\text { First-line treatment regimen that NMTG recommends for children } \\
\text { under } 15 \text { years }\end{array}$} \\
\hline ASAQ & 7 & 63.64 & 9 & 75.00 & \\
\hline Quinine & 0 & 0.00 & 2 & 16.67 & \\
\hline Other & 4 & 36.36 & 1 & 8.33 & 0.134 \\
\hline
\end{tabular}

First-line treatment guideline recommended by the NMTG before transferring

$\begin{array}{llrrrr}\text { AS suppositories } & 1 & 9.09 & 1 & 8.33 & \\ \text { No correct treatments } & 7 & 63.64 & 7 & 58.33 & \\ \text { Don't know } & 3 & 27.27 & 4 & 33.33 & 0.100\end{array}$

First-line treatment regimen recommended by the NMTG for the treatment of severe malaria

$\begin{array}{lrrrrr}\text { AS iv and, when tolerated, oral ASAQ } & 3 & 27.27 & 9 & 75.00 & \\ \text { Other } & 7 & 63.64 & 3 & 25.00 & \\ \text { Don't know } & 1 & 9.09 & 0 & 0.00 & 0.062\end{array}$

Do you have any difficulty in applying the protocols proposed by the NMTG?

$\begin{array}{llllll}\text { No } & 8 & 72.73 & 7 & 58.33 & \\ \text { Yes } & 3 & 27.27 & 5 & 41.67 & 0.389\end{array}$

What are the main difficulties in applying the protocols in the NMTG?

$\begin{array}{lrrrrr}\text { Presence of adverse effects } & 2 & 66.67 & 0 & 0.00 & 0.344 \\ \begin{array}{l}\text { The patient does not like the treat- } \\ \text { ment }\end{array} & 0 & 0.00 & 2 & 40.00 & 0.162 \\ \begin{array}{l}\text { Emergence of resistance } \\ \text { Lack of availability }\end{array} & 1 & 33.33 & 1 & 20.00 & 0.591 \\ & 0 & 0.00 & 2 & 40.00 & 0.162\end{array}$

Do you think that any change in the pattern of the NMTG protocol is necessary?

\begin{tabular}{lrrrrr} 
No & 8 & 72.73 & 10 & 83.33 & \\
Yes & 3 & 27.27 & 2 & 16.67 & 0.64 \\
\hline
\end{tabular}

Following these results, a regression analysis was carried out to look for associations between the knowledge index of the practitioners and each of their sociodemographic characteristics. Prescribers with a medical degree, working at the hospital and visiting more than 11 malaria cases per day had a better knowledge of malaria and the NMTG, whilst years of experience were inversely associated with the level of knowledge (Table 5).

\section{Discussion}

Adequate practices and knowledge about malaria and the NMTG are decisive in terms of ensuring proper management and the control of the disease [4]. However, low compliance with malaria national protocols by healthcare workers remains a problem in many countries in sub-Saharan Africa [19, 20]. Most practitioners working at public health facilities have a low level of knowledge regarding the National Malaria Treatment Guidelines (NMTG) in the Bata District of Equatorial Guinea. However, important differences between hospital and health centre workers were found. This study has found that better diagnostic, treatment practices, knowledge of malaria, the NMTG and treatment resistances was higher amongst hospital workers than amongst practitioners at health centres.

As in most African countries [3, 21], practitioners' knowledge about malaria transmission, signs and symptoms was, in general, good. Although workers at the health centres mentioned more symptoms, convulsions related with severe malaria were mentioned significantly more by practitioners working at the regional hospital. Commonly, cases of severe malaria are more frequently seen at hospitals than at health centres [22].

Effective case management at public health facilities is one of the cornerstones of malaria control. Since 2012, the WHO has advised that clinical diagnoses should be confirmed by parasitological methods (6). In the Bata District, clinical diagnosis was the malaria diagnosis method most used by health centre workers, while confirmation by microscopy was mostly cited by those who worked at the regional hospital. Regarding RDTs, these were mentioned significantly more by the health centre workers Symptomatology continues to be more predominant for diagnosis than any laboratory test in most parts of Africa [23] and, frequently, practitioners request parasitology confirmation, but then pay little attention even to negative results, continuing to treat children as a malaria case [24].

Concerning knowledge and practices regarding malaria treatment, practitioners mentioned a wide range of different treatments for uncomplicated malaria in children under 15 years old, including treatments not recommended in the NMTG and former treatments, such as chloroquine. Concerning the treatment they prescribe most for uncomplicated malaria, intramuscular artemether was the therapy most mentioned by health centre workers, while AL was most frequently mentioned by workers at the regional hospital. Despite the fact that most of them knew that the first-line treatment in Equatorial Guinea is ASAQ, the side-effects were the main reason why they did not prescribe it. The same reasons and preference for AL compared to ASAQ has 
Table 5 Knowledge index and socio demographic characteristics

\begin{tabular}{|c|c|c|c|c|c|}
\hline & Low & High & $P$ value & OR & $95 \% \mathrm{Cl}$ \\
\hline \multicolumn{6}{|l|}{ Sex } \\
\hline Male & 10 & 5 & & & \\
\hline Female & 17 & 12 & 0.427 & 1.41 & $(0.38-5.20)$ \\
\hline \multicolumn{6}{|l|}{ Age } \\
\hline$<35$ & 11 & 10 & & & \\
\hline$>36$ & 16 & 7 & 0.195 & 0.48 & $(0.14-1.65)$ \\
\hline \multicolumn{6}{|l|}{ Academic level } \\
\hline Medical degree & 14 & 2 & & & \\
\hline Others & 13 & 15 & 0.007 & 8.08 & $(1.54-42.37)$ \\
\hline \multicolumn{6}{|l|}{ Years of experience } \\
\hline$<3$ & 12 & 13 & & & \\
\hline$>4$ & 15 & 4 & 0.037 & 0.25 & $(0.06-0.10)$ \\
\hline \multicolumn{6}{|l|}{ Malaria cases/day } \\
\hline$<12$ & 19 & 7 & & & \\
\hline$>13$ & 8 & 10 & 0.055 & 3.39 & $(0.95-12.09)$ \\
\hline \multicolumn{6}{|c|}{$<15$ years old malaria cases/day } \\
\hline$<11$ & 22 & 7 & & & \\
\hline$>12$ & 5 & 10 & 0.008 & 6.29 & $(1.60-24.73)$ \\
\hline \multicolumn{6}{|l|}{ Health facility } \\
\hline Health centre & 20 & 6 & & & \\
\hline Hospital & 7 & 11 & 0.013 & 5.24 & $(1.41-19.52)$ \\
\hline
\end{tabular}

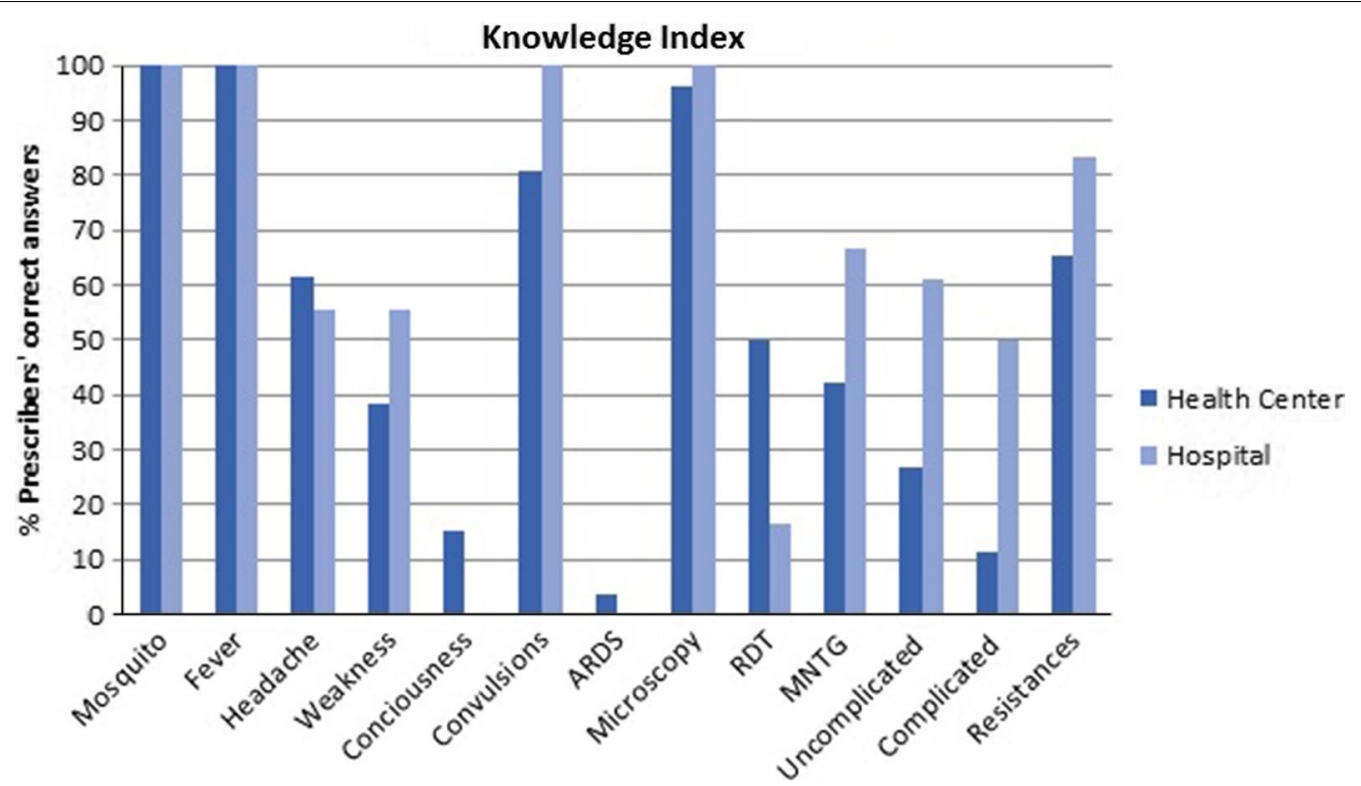

Fig. 1 Knowledge index. Malaria and NMTG knowledge among public health prescribers in Bata District. (Mosquito): Malaria is transmitted by a mosquito bite. (Fever, Headache and Weakness): Fever, headache and weakness are symptoms of uncomplicated malaria. (Consciousness and Convulsions, ARDS): Loss of consciousness, convulsions and Acute Respiratory Distress Syndrome are symptoms of complicated malaria. (NTG): NMTG awareness. (Uncomplicated): NMTG's first-line treatment for uncomplicated malaria. (Complicated): NMTG's first-line treatment for complicated malaria. (Resistance): Anti-malarial resistance 
been described in many countries in the region $[25,26]$. The use of injectable AM as a treatment for uncomplicated malaria has only been described in Sudan $[27,28]$ and Equatorial Guinea [15, 29]. This use of artemisinin monotherapy to treat uncomplicated malaria can contribute to the emergence of resistance to ACT and lead to treatment failure [30]. In the Bata District, public health practitioners knew about the existence of resistance to chloroquine, mostly mentioned by health centre practitioners, and resistance to AM mostly mentioned by hospital health workers, in accordance with the inadequate use of injectable AM by the practitioners at health centres [15].

The workers at the health centres said that they knew the National Malaria Treatment Guidelines, through a colleague. However, most of the practitioners working at the hospital knew the NMTG through specific MISABS training. The NMTG was introduced in the Continental Region of Equatorial Guinea in 2008, but, up until the time of this study, no reinforcement or follow-up training had been offered to malaria practitioners working at health centres regarding the national protocols for malaria management.

Despite this, ASAQ first-line treatment for children with uncomplicated malaria was well-known by those practitioners who knew the NMTG at both health facilities, although the first-line treatment for severe malaria was almost unknown to practitioners at the health centres. This could be also caused by the fact that this form of malaria is not meant to be treated at health centres, since it should be immediately referred to the hospital. Unfortunately, most of the practitioners at the health centres were also unaware of the malaria treatment protocol recommended before transferring the patient to the hospital [17]. Once again, knowledge regarding malaria case management must be improved in the Bata District of Equatorial Guinea through training if the aim is to achieve malaria control. Various initiatives implemented in other African countries could be taken into account [31].

The index of knowledge regarding malaria and the recommendations included in the NMTG of Equatorial Guinea is low amongst most health practitioners in the Bata District, being higher among hospital practitioners, who have fewer years of experience than the practitioners at the health centres, but who possess a higher degree of academic education. Low knowledge regarding malaria protocols is frequent in many African countries [32, $33]$, both in the private and public sector [8, 19, 34. 35]. Usually, the factors that influence local health workers' knowledge of malaria frequently include education and working experience [33]. The comparison with regard to years of working experience reveals that practitioners with fewer years of working experience are more likely to have a solid knowledge of malaria than those with greater experience, due to the fact that they have received more recent and up-to-date training [13].

This study consisted of a cross-sectional survey of the Bata District, so the main limitation is that the results may not be generally applicable to the rest of the country, even when low compliance with first-line malaria treatment throughout the country is one of the main concerns of the National Programme for Malaria Control (NPMC).

\section{Conclusions}

Practitioners at the Bata Regional Hospital had a higher knowledge of malaria and better practices than those working at the health centres. However, general knowledge about malaria and the National Malaria Treatment Guidelines is low in both groups. It is, therefore, essential to reinforce practitioners' knowledge and use of the NMTG in order to improve malaria case management and disease control in the region.

\begin{abstract}
Acknowledgements
The authors would like to thank the study participants for volunteering and the data gatherers for their work in the field. They would also like to recognize the contribution of the Global Health Programme at the National Centre of Tropical Medicine (in Equatorial Guinea) in terms of providing logistical and technical support, and thank the Ministry of Health and Social Welfare of Equatorial Guinea for generating a favorable environment for the field work. Special thanks also go to the Spanish International Cooperation Agency for Development (AECID) and the Spanish State Foundation for Health, Childcare and Social Welfare (FCESAI) for enabling us to carry out this study. The corresponding author's affiliation centre belongs to the Tropical Diseases Research Network (RICET) RD16CIII/0003/0001.
\end{abstract}

\section{Authors' contributions}

MRB and BG designed and coordinated the study. PSS and JN carried out the survey. MRB conceived and designed the data analysis methods. MR coordinated the EG Malaria Programme and participated in survey coordination. PB, $A B$ and $P N$ participated in survey coordination and reviewed the manuscript. $\mathrm{MB}$ and MRB performed the data analyses and wrote the manuscript. PB and PSS reviewed and corrected the manuscript. All authors read and approved the final manuscript.

\section{Funding}

This study was funded by the by the Agencia Española de Cooperación Internacional.

AECID2017/CTR/0900237 (https://www.aecid.es/ES), the Spanish State Foundation for Health, Childcare and Social Welfare (FCESAI) and the Tropical Diseases Research Network RD16CIII/003/001RICET (https://www.ricet.es). The funders had no role in study design, data collection and analysis, decision to publish, or preparation of the manuscript.

\section{Availability of data and materials}

All data generated or analysed during this study are included in this published article.

\section{Ethics approval and consent to participate}

This study was approved by the Ministry of Health and Social Welfare of Equatorial Guinea and the Ethics Committee of the Spanish Carlos III National Health Institute (CEI PI 71_2017). Written informed consent was obtained from all participants in the study.

Consent for publication

Not applicable. 


\section{Competing interests}

The authors declare that they have no competing interests.

\section{Author details}

${ }^{1}$ Centro Nacional de Medicina Tropical, Instituto de Salud Carlos III, Madrid, Spain. ${ }^{2}$ Servicio de Medicina Preventiva, Hospital Virgen de la Salud, Toledo, Spain. ${ }^{3}$ Servicio de Medicina Preventiva, Hospital Clínico San Carlos, Madrid, Spain. ${ }^{4}$ Fundación Estatal, Salud, Infancia y Bienestar Social (FCSAI), Madrid, Spain. ${ }^{5}$ Ministerio de Salud y Bienestar Social, Malabo, Equatorial Guinea. ${ }^{6}$ Red de Investigación Colaborativa en Enfermedades Tropicales, RICET, Madrid, Spain.

Received: 20 June 2020 Accepted: 27 November 2020

Published online: 07 January 2021

\section{References}

1. WHO. World Malaria Report 2019. Geneva: World Health Organization, 2019. https://www.who.int/news-room/feature-stories/detail/world -malaria-report-2019. Accessed 14 Jan 2020.

2. Afoakwah $C$, Deng $X$, Onur I. Malaria infection among children under five: the use of large-scale interventions in Ghana. BMC Public Health. 2018:18:536.

3. Landier J, Parker DM, Thu AM, Carrara VI, Lwin KM, Bonnington CA, et al. the role of early detection and treatment in malaria elimination. Malar J. 2016;15:363.

4. Guerra-Neira A, Rubio JM, Royo JR, Ortega JC, Auñón AS, Diaz PB, et al Plasmodium diversity in non-malaria individuals from Bioko Island in Equatorial Guinea (West Central Africa). Int J Health Geogr. 2006;5:27.

5. Nankabirwa J, Brooker SJ, Clarke SE, Fernando D, Gitonga CW, Schellenberg D, et al. Malaria in school-age children in Africa: an increasingly important challenge. Trop Med Int Health. 2014;19:1294-309.

6. World Health Organization. Guidelines for the Treatment of Malaria. 3rd ed. Geneva: World Health Organization; 2015. (10.1080/07293682.1982. 9658069).

7. WHO. Emergence and spread of artemisinin resistance: calls for intensified efforts to withdraw oral artemisinin-based monotherapy from the market. Geneva: World Health Organization, 2020. http://www.who.int/ malaria/publications/atoz/policy-brief-withdrawal-of-oral-artemisini n-based-monotherapies/en/. Accessed 14 Jan 2020.

8. Obiebi IP. Adherence to antimalarial drug policy among doctors in Delta State, Nigeria: implications for malaria control. Ghana Med J. 2019;53:109.

9. WHO. World Malaria Report 2018. Geneva: World Health Organization, 2018. http://www.who.int/malaria/publications/world-malaria-repor t-2018/report/en/. Accessed 14 Jan 2020.

10. Shahandeh K, Basseri HR, Majdzadeh R, Sadeghi R, Safari R, Shojaeizadeh D. Health workers adjustment for elimination of malaria in a low endemic area. Int J Prev Med. 2015;6:105.

11. Shey ND, Clement AN, Muluh N, Wung ABA, Ivo KK. Community health workers' knowledge, attitudes and practices regarding malaria control and prevention in Bamenda, Cameroon: a Community-Based Study. J Health Med Inform. 2017:8:5.

12. Regmi K, Kunwar A, Ortega L. A systematic review of knowledge, attitudes and beliefs about malaria among the South Asian Population. Infect Ecol Epidemiol. 2016;6:30822.

13. Wang R, Tang S, Yang J, Shao T, Shao O, Liu C, et al. Improving local health workers' knowledge of malaria in the elimination phase-determinants and strategies: a cross-sectional study in rural China. Malar J. 2017;16:210.

14. Mangham LJ, Cundill B, Ezeoke O, Nwala E, Uzochukwu BS, Wiseman V, et al. Treatment of uncomplicated malaria at public health facilities and medicine retailers in South-eastern Nigeria. Malar J. 2011;10:155.

15. Suárez-Sánchez P, García B, Nzang J, Ncogo P, Riloha M, Berzosa P, et al. Failures in the case management of children with uncomplicated malaria in the Bata District of Equatorial Guinea and associated factors. PLOS ONE. 2019;14:e0220789.

16. Ncogo P, Herrador Z, Romay-Barja M, Garcia-Carrasco E, Nseng G, Berzosa $P$, et al. Malaria prevalence in Bata district, Equatorial Guinea: a crosssectional study. Malar J. 2015;14:456.

17. Ministerio de Sanidad y Bienestar Social, Guía Terapeútica Nacional del Paludismo en Guinea Ecuatorial. Malabo: Ministerio de Sanidad y Bienestar Social; 2014
18. Dhawan G, Joseph N, Pekow PS, Rogers CA, Poudel KC, Bulzacchelli MT. Malaria-related knowledge and prevention practices in four neighbourhoods in and around Mumbai, India: a cross-sectional study. Malar J. 2014;13:303.

19. Namuyinga RJ, Mwandama D, Moyo D, Gumbo A, Troell P, Kobayashi $M$, et al. Health worker adherence to malaria treatment guidelines at outpatient health facilities in Southern Malawi following implementation of universal access to diagnostic testing. Malar J. 2017;16:40.

20. Zurovac D, Rowe AK, Ochola SA, Noor AM, Midia B, English M, et al. Predictors of the quality of health worker treatment practices for uncomplicated malaria at Government Health Facilities in Kenya. Int J Epidemiol. 2004;33:1080-91

21. Asante KP, Abokyi L, Zandoh C, Owusu R, Awini E, Sulemana A, et al. Community perceptions of malaria and malaria treatment behaviour in a rural district of Ghana: implications for artemisinin combination therapy. BMC Public Health. 2010;10:409.

22. WHO. Severe malaria. Trop Med Int Health. 2014;19(Suppl. 1):7-131.

23. Ezeoke OP, Ezumah NN, Chandler CC, Mangham-Jefferies LJ, Onwujekwe OE, Wiseman $V$, et al. Exploring health providers' and community perceptions and experiences with malaria tests in South-East Nigeria: a critical step towards appropriate treatment. Malar J. 2012;11:368.

24. Reyburn H, Mbakilwa H, Mwangi R, Mwerinde O, Olomi R, Drakeley C, et al. Rapid diagnostic tests compared with malaria microscopy for guiding outpatient treatment of febrile illness in Tanzania: randomised trial. BMJ. 2007;334:403.

25. Banek K, Webb EL, Smith SJ, Chandramohan D, Staedke SG. Adherence to treatment with artemether-lumefantrine or amodiaquine-artesunate for uncomplicated malaria in children in Sierra Leone: a randomized trial. Malar J. 2018;17:222.

26. Bassi PU, Osakwe Al, Isah A, Suku I, Kalat M, Jalo I, et al. Safety of artemisinin-based combination therapies in Nigeria: a cohort event monitoring study. Drug Saf. 2013;36:747-56.

27. Bilal JA, Gasim Gl, Abdien MT, Elmardi KA, Malik EM, Adam I. Poor adherence to the malaria management protocol among health workers attending under-five year old febrile children at Omdurman Hospital, Sudan. Malar J. 2015;14:34.

28. Abdelgader TM, Githinji S, Zurovac D, Snow RW, Elmardi KA, Ibrahim AM, et al. Progress towards implementation of ACT malaria case-management in public health facilities in the Republic of Sudan: a cluster-sample survey. BMC Public Health. 2012;12:11.

29. Romay-Barja M, Jarrin I, Ncogo P, Nseng G, Sagrado MJ, Santana-Morales MA, et al. Rural-urban differences in household treatment-seeking behaviour for suspected malaria in children at Bata District, Equatorial Guinea. PLOS ONE. 2015;10:e0135887.

30. ACTwatch Group, Ujuju C, Anyanti J, Newton PN, Ntadom G. When it just won't go away: oral artemisinin monotherapy in Nigeria, threatening lives, threatening progress. Malar J. 2017;16:489.

31. Juma E, Zurovac D. Changes in health workers' malaria diagnosis and treatment practices in Kenya. Malar J. 2011;10:1.

32. Argaw MD, Mavundla TR, Gidebo KD. Management of uncomplicated malaria in private health facilities in North-West Ethiopia: a clinical audit of current practices. BMC Health Serv Res. 2019;19:932.

33. Gathara D, English M, van Hensbroek MB, Todd J, Allen E. Exploring sources of variability in adherence to guidelines across hospitals in lowincome settings: a multi-level analysis of a cross-sectional survey of 22 hospitals. Implementation Sci. 2015;10:60.

34. Salomão CA, Sacarlal J, Chilundo B, Gudo ES. Prescription practices for malaria in Mozambique: poor adherence to the national protocols for malaria treatment in 22 public health facilities. Malar J. 2015;14:483.

35. Randriatsarafara FM, Mandrosovololona V, Andrianirinarison JC, Rakotondrandriana AN, Randrianarivo-Solofoniaina AE, Ratsimbasoa A, et al. [Adherence of private sector providers to uncomplicated malaria management policy in Madagascar] (in French). Pan Afr Med J. 2019;32:79.

\section{Publisher's Note}

Springer Nature remains neutral with regard to jurisdictional claims in published maps and institutional affiliations. 